Pacific Journal of Mathematics

SPECIAL SEMIGROUPS ON THE TWO-CELL 


\section{SPECIAL SEMIGROUPS ON THE TWO-CELL}

\section{EsMond DeVun}

A commutative semigroup $S$ has property $(\alpha)$ if (1) $S$ is topologically a two-cell, (2) $S$ has no zero divisors, and (3) the boundary of $S$ is the union of two unit intervals with the usual multiplication. A characterization of semigroups having property $(\alpha)$ will be given. Let $(I, \cdot)$ denote the closed unit interval with the usual multiplication. Let $M$ be a closed ideal of $(I, \cdot) \times(I, \cdot)$ such that $M$ contains $(I \times\{0\}) \cup(\{0\} \times I)$, and $M \cap(I \times\{1\})=\{(0,1)\}$ or $M \cap(\{1\} \times I)=\{(1,0)\}$. For each $a, b \in(0,1)$ define a relation $R(a, b ; M)$ on $(I, \cdot) \times(I, \cdot)$ by $(x$, $y) \in R(a, b ; M)$ if (1) $x=y$ or $(2) x, y \in(I \times\{0\}) \cup(\{0\} \times I)$, or (3) there exists an $s \in(0, \infty)$ such that $x$ and $y$ are in the same component of $M \cap\left\{\left(a^{s t}, b^{s-s t}\right): 0 \leqq t \leqq 1\right\}$.

Lemma. The relation $R(a, b ; M)$ is a closed congruence.

Theorem. A semigroup $S$ has property $(\alpha)$ if and only if there exists $a, b, M$ such that $(I, \cdot) \times(I, \cdot) / R(a, b ; M)$ is iseomorphic to $S$.

A central problem in the theory of topological semigroups is to characterize those semigroups whose underlying space is fixed. In general this problem is much too difficult; however, in some special cases considerable progress has been made. For example semigroups on the unit interval with identities are completely classified in [3], [4], and [7]. Some special cases on the two-cell have also been investigated [1], [2], [5], [6] and [7].

In this paper we are concerned with commutative semigroups having property $(\alpha)$. A semigroup $S$ has property $(\alpha)$ if $(1) S$ is topologically a two-cell, (2) $S$ has no zero divisors, and (3) the boundary of $S$ is the union of two unit intervals with the usual multiplication. A description of commutative semigroups satisfying property $(\alpha)$ will be given.

We begin by giving a method of constructing commutative semigroups having property $(\alpha)$. We will show later that this method yields all commutative semigroups having property $(\alpha)$.

Let $(I, \cdot)$ denote the closed unit interval with the usual multiplication. Let $M$ be a closed ideal of $(I, \cdot) \times(I, \cdot)$ such that $M$ contains $(I \times\{0\}) \cup(\{0\} \times I)$ and $M \cap(I \times\{1\})=\{(0,1)\}$ or $M \cap(\{1\} \times I)=$ $\{(1,0)\}$. For $a, b$ contained in the open interval $(0,1)$ define the relation $R(a, b ; M)$ on $(I, \cdot) \times(I, \cdot)$ by $(x, y) \in R(a, b ; M)$ if (1) $x=y$ or (2) $x, y \in(I \times\{0\}) \cup(\{0\} \times I)$ or (3) there exists an $s$ contained in the positive reals such that $x$ and $y$ are in the same component of 
$M \cap\left\{\left(a^{s t}, b^{s-s t}\right): 0 \leqq t \leqq 1\right\}$

Lemma 1. The relation $R(a, b ; M)$ is a closed congruence, and hence $(I, \cdot) \times(I, \cdot) / R(a, b ; M)$ is a semigroup.

Proof. We will first show $R(a, b ; M)$ is closed. Let $\left(\hat{r}_{n}, \hat{s}_{n}\right) \in$ $R(a, b ; M)$ for $n=1,2,3, \cdots$, with $\left(\hat{r}_{n}, \hat{s}_{n}\right) \rightarrow(\hat{r}, \hat{s})$. If an infinite number of the elements of the sequence satisfy (1) or $(2)$, then $(\hat{r}, \hat{s}) \in$ $R(a, b ; M)$. Hence we can assume all of the elements of the sequence satisfy (3). This implies there exist sequences $w_{n}, c_{n}, d_{n}$ such that $\hat{r}_{n}=\left(a^{w_{n} c_{n}}, b^{w_{n}-w_{n} c_{n}}\right)$ and $\hat{s}_{n}=\left(a^{w_{n} d_{n}}, b^{w_{n}-w_{n} d_{n}}\right)$ where $w_{n}$ is a positive real number and $c_{n}, d_{n} \in[0,1]$. Since $\hat{r}_{n} \rightarrow \widehat{r}$ and $\hat{s}_{n} \rightarrow \hat{s}$, we have either (a) $w_{n} \rightarrow \infty$ or (b) $w_{n} \rightarrow w \in(0, \infty), c_{n} \rightarrow c$ and $d_{n} \rightarrow d$. If (a) holds we have $a^{w_{n} c_{n}} \rightarrow 0$ or $b^{w_{n}-w_{n} c_{n}} \rightarrow 0$, and $a^{w_{n} d_{n}} \rightarrow 0$ or $b^{w_{n}-w_{n} d_{n}} \rightarrow 0$, hence $\hat{r}, \hat{s} \in(\{0\} \times I) \cup(I \times\{0\})$ and $(\hat{r}, \hat{s}) \in R(a, b ; M)$. If (b) holds we use the fact that $\left(a^{w_{n} e_{n}}, b^{w_{n}-w_{n} e_{n}}\right) \in M$ for any $e_{n}$ satisfying $\min \left(c_{n}, d_{n}\right) \leqq e_{n} \leqq \max \left(c_{n}, d_{n}\right)$. Let it be the case that $\min (c, d) \leqq$ $e \leqq \max (c, d)$. Then there exists a sequence such that $\min \left(c_{n}, d_{n}\right) \leqq$ $e_{n} \leqq \max \left(c_{n}, d_{n}\right)$ and $e_{n} \rightarrow e$. Since $\left(a^{w_{n} e_{n}}, b^{w_{n}-w_{n} e_{n}}\right) \in M$ and $M$ is closed we obtain $\left(a^{w_{n} e_{n}}, b^{w_{n}-w_{n} e_{n}}\right) \rightarrow\left(a^{w e}, b^{w-w e}\right) \in M$. Hence $\hat{r}$ and $\hat{s}$ are in the same component of $\left(M \cap\left\{\left(a^{w t}, b^{w-w t}\right): 0 \leqq t \leqq 1\right\}\right)$, which implies $(\hat{r}, \hat{s}) \in R(a, b ; M)$.

To show that $R(a, b ; M)$ is a congruence, after a moments reflection, it becomes clear that we need only show $((x, 1) \hat{r},(x, 1) \hat{s})$ satisfies property (3) whenever $(\hat{r}, \hat{s})$ satisfies property (3) and $0<x<1$. Let $\hat{r}=\left(a^{w c}, b^{w-w c}\right)$ and $\hat{s}=\left(a^{w d}, b^{w-w d}\right)$ with $c \leqq d$. Also $\left\{\left(a^{w e}, b^{w-w e}\right): c \leqq\right.$ $e \leqq d\} \subset M$. Since $0<x<1$, there exist a $q \in(0, \infty)$ such that $\left(a^{q}, 1\right)=(x, 1)$. Using the fact that $M$ is an ideal of $(I, \cdot) \times(I, \cdot)$ we see that

$$
(x, 1)\left(a^{w e}, b^{w-w e}\right)=\left(a^{q}, 1\right)\left(a^{w e}, b^{w-w e}\right)=\left(a^{q+w e}, b^{w-w e}\right)=\left(a^{m f}, b^{m-m f}\right) \in M
$$

for $m=q+w$ and $f=e w+q / w+q$ and $c \leqq e \leqq d$. This completes the proof.

One can observe that the map $\varphi:(I, \cdot) \times(I, \cdot) \rightarrow(I, \cdot) \times(I, \cdot) / R$ $(a, b ; M)$ which sends elements to their equivalence classes is a monotone map, and no equivalence class of $R(a, b ; M)$ separates $(I, \cdot) \times(I, \cdot)$. A theorem of Whyburn [8] reveals that $(I, \cdot) \times(I, \cdot) / R(a, b ; M)$ is a two-cell. Also since $(I, \cdot) \times(I, \cdot) / R(a, b ; M)$ is the homomorphic image of $(I, \cdot) \times(I, \cdot)$ which is commutative, it is commutative. Furthermore, the boundary of $(I, \cdot) \times(I, \cdot) / R(a, b ; M)$ equals $\varphi((I, \cdot) \times\{1\}) \cup$ $\varphi(\{1\} \times(I, \cdot))$, and hence is the union two unit intervals with usual multiplication. Finally since $(I \times\{0\}) \cup(\{0\} \times I)$ is a completely prime 
ideal of $(I, \cdot) \times(I, \cdot),(I, \cdot) \times(I, \cdot) / R(a, b ; M)$ has no zero divisors. Thus we have proved the following:

THEOREM A. $(I, \cdot) \times(I, \cdot) / R(a, b ; M)$ is a commutative semigroup satisfying property $(\alpha)$.

Now we will take a commutative semigroup $S$ satisfying property $(\alpha)$ and find $a, b \in(0,1)$ and an ideal $M$ such that $(I, \cdot) \times(I, \cdot) / R(a, b ; M)$ is iseomorphic to $S$.

We begin this section by letting the boundary of $S$ equal $U \cup V$ where $U$ and $V$ are unit intervals with the usual multiplication. Without much difficulty it can be shown that $S=U \cdot V$ and $U \cap V=$ $\{z, i\}$ where $z$ is the zero for $S$ and $i$ is the identity for $S$. Letting $f:(I, \cdot) \rightarrow U$ and $g(I, \cdot) \rightarrow V$ be iseomorphisms and defining $h:(I, \cdot) \times$ $(I, \cdot) \rightarrow S$ by $h(x, y)=f(x) \cdot g(y)$, we see that $h$ is a continuous homomorphism from $(I, \cdot) \times(I, \cdot)$ onto $S$.

LEMMA 2. If $h\left(x_{1}, y_{1}\right)=h\left(x_{2}, y_{2}\right) \neq z$, then one and only one of the following holds:

(1) $x_{1}=x_{2}$ and $y_{1}=y_{2}$

(2) $\left(x_{1}-x_{2}\right)\left(y_{1}-y_{2}\right)<0$.

Proof. Let $h\left(x_{\jmath}, 1\right)=u_{j}$ and $h\left(1, y_{j}\right)=v_{j}, j=1,2$. If (1) is not true, then suppose $x_{1}>x_{2}$. This is the case if and only if there exist $u \in U, u \neq i$ such that $u u_{1}=u_{2}$. Now $y_{1} \geqq y_{2}$ if and only if there exist $v$ such that $v v_{1}=v_{2}$. Since $h\left(x_{1}, y_{2}\right)=h\left(x_{2}, y_{2}\right)$ we have $u_{1} v_{1}=$ $u_{2} v_{2}$ or $u_{1} v_{1}=\left(u_{1} v_{1}\right)(u v)$ which implies $u_{2} v_{1}=\left(u_{1} v_{1}\right) \cdot u^{n} \cdot v^{n}$ for $u=1,2$, $3, \cdots$. Hence, $u_{1} v_{2}=\left(u_{1} v_{1}\right) \cdot \lim u^{n} \cdot \lim v^{n}=z$. This is a contradiction. Note for $x \neq 0,\{h(x, y): 0 \leqq y \leqq 1\}$ is an are in $S$.

Lemma 3. If $s \in S \backslash\{z\}$, then there exist $\left(x_{1}, y_{1}\right),\left(x_{2}, y_{2}\right) \in h^{-1}(s)$ such that for all $(x, y) \in h^{-1}(s)$ we have $x_{2} \geqq x \geqq x_{2}$ and $y_{2} \geqq y \geqq y_{1}$.

Proof. Set $x_{1}=\sup \{x: h(x, y)=s\}$. Construct a sequence $\left(q_{n}, v_{n}\right) \in$ $h^{-1}(s)$ with $q_{n \div 1} \geqq q_{n}$ such that $\lim q_{n}=x_{-}$. Noting that $r_{n \div 1} \leqq r_{n}$, set $y_{1}=\lim r_{n}$. Since $s=h\left(q_{n}, r_{n}\right)$ and $\left(q_{n}, r_{n}\right) \rightarrow\left(x_{1}, y_{1}\right)$ we have $h\left(x_{1}, y_{1}\right)=$ $\lim h\left(q_{n}, r_{n}\right)=s$. This implies $x_{2}$ is the maximum $x$ and $y_{1}$ is the minimum $y$ such that $h(x, y)=s$. A similar argument yields an $\left(x_{2}, y_{2}\right) \in$ $h^{-1}(s)$.

Lemma 4. If $s \in S \backslash\{z\}$, then $\pi_{1}\left(h^{-1}(s)\right)$ is connected.

Proof. Let $x_{1}<x<x_{2}$ with $\left(x_{1}, y_{1}\right),\left(x_{2}, y_{2}\right) \in h^{-1}(s)$. We will show 
there exist a $\bar{y}$ such that $h(x, \bar{y})=s$. The arc $\{h(x, y): 0 \leqq y \leqq 1\}$ must intersect one of the two arcs $\left\{h\left(x_{1}, y\right): y_{1} \leqq y \leqq 1\right\}$ and $\left\{h\left(x_{2}, y\right)\right.$ : $\left.y_{2} \leqq y \leqq 1\right\}$. Suppose it intersects the latter, then there exist $y, y^{\prime}$ such that $h\left(x, y^{\prime}\right)=h\left(x_{2}, y\right)$. Hence, if one chooses $\bar{y}=y^{\prime} y^{\prime \prime}$ where $y y^{\prime \prime}=y_{2}$, then $h(x, \bar{y})=h\left(x, y^{\prime} y^{\prime \prime}\right)=h\left(x, y^{\prime}\right) h\left(1, y^{\prime \prime}\right)=h\left(x_{2}, y\right) h\left(1, y^{\prime \prime}\right)=$ $h\left(x_{2}, y y^{\prime \prime}\right)=h\left(x_{2}, y_{2}\right)=s$. This completes the proof.

REMARK 1. By using Lemma 2 we note that the $\bar{y}$ obtained in the proof above is unique.

Lemma 5. If $s \in S \backslash\{z\}$, then for all $\left(x_{1}, y_{1}\right),\left(x_{2}, y_{2}\right) \in h^{-1}(s)$ we have $\left(\sqrt{x_{1} x_{2}}, \sqrt{y_{1} y_{2}}\right) \in h^{-1}(s)$.

Proof. Suppose $x_{2}>x_{1}$, then $x_{1}<\sqrt{x_{1} x_{2}}<x_{2}$, and there exist a unique $y$ such that $h\left(\sqrt{x_{1} x_{2}}, y\right)=s$. Now $s^{2} \neq z$, and $h\left(x_{1} x_{2}, y_{1} y_{2}\right)=$ $s^{2}=h\left(x_{1} x_{2}, y^{2}\right)$. Hence $y=\sqrt{y_{1} y_{2}}$.

REMARK 2. Note that $h^{-1}(z)=I \times\{0\} \cup\{0\} \times I$.

Lemma 6. If $s \in S \backslash\{z\}$, then there exist $\left(x_{1}, y_{1}\right),\left(x_{2}, y_{2}\right) \in h^{-1}(s)$ such that $h^{-1}(s)=\left\{\left(x_{1}^{t} x_{2}^{1-t}, y_{1}^{t} y_{2}^{1-t}\right): 0 \leqq t \leqq 1\right\}$.

Proof. Let $\left(x_{1}, y_{1}\right),\left(x_{2}, y_{2}\right)$ be the ordered pairs obtained in Lemma 3. By inducting on the previous lemma we see $\left\{\left(x_{1}^{d} x_{2}^{1-d}, y_{1}^{d} y_{2}^{1-d}\right): 0 \leqq d \leqq\right.$ $1, d$ a dyadic rational $\} \subset h^{-1}(s)$. Taking the closure of this set we get $\left\{\left(x_{1}^{t} x_{2}^{1-t}, y_{1}^{t} y_{2}^{1-t}\right): 0 \leqq t \leqq 1\right\} \subseteq h^{-1}(s)$. Since $h^{-1}(s)$ cannot property include this set, they are equal.

Let $J=\left\{s: s \in S\right.$ and $h^{-1}(s)$ is not a point $\}$. Note that $J$ is an ideal of $S$, and hence $h^{-1}(J)$ and $h^{-1}(J)^{*}$ are ideals of $(I, \cdot) \times(I, \cdot)$.

Lemma 7. If $s \in J \backslash\{z\}$, then there exist $a, b \in(0,1)$ such that $h^{-1}(s) \subset$ $\left\{\left(a^{t}, b^{1-t}\right): 0 \leqq t \leqq 1\right\}$.

Proof. Let $\left(x_{1}, y_{1}\right),\left(x_{2}, y_{2}\right)$ be the ordered pairs obtained in Lemma 3. We know $x_{1}>x_{2}>0$ and $y_{2}>y_{1}>0$. Both $x_{1}$ and $y_{2}$ cannot be equal to 1 for if both were we would have $h\left(1, y_{1}\right)=h\left(x_{2}, 1\right)$ contradicting the fact that $U \cap V=\{z, i\}$. We shall assume $y_{2} \neq 1$, hence there exist $\beta$ such that $0<\beta<1$ and $y_{1}^{1-\beta}=y_{2}$, also $0<x_{1} \leqq 1$ and hence there exist $\gamma$ such that $0 \leqq \gamma<1$ and $x_{2}^{r}=x_{1}$. Setting $a=$ $\left(x_{2} x_{1}^{\beta-1}\right)^{1 / 3}$ and $b=\left(y_{2}^{-\gamma} y_{1}\right)^{1 /(1-\gamma)}$, it can be shown by simple algebraic manipulation that $a, b \in(0,1)$ and $h^{-1}(s) \subset\left\{\left(a^{t}, b^{1-t}\right): 0 \leqq t \leqq 1\right\}$.

Note that there exist $t_{1}$ and $t_{2}$ such that $h^{-1}(s)=\left\{\left(a^{t}, b^{1-t}\right): 0 \leqq\right.$ $\left.t_{1} \leqq t \leqq t_{2} \leqq 1\right\}$. 
We will now show that the $a, b \in(0,1)$ obtained in the previous theorem is somewhat unique.

Lemma 8. If $s, s^{\prime} \in J \backslash\{z\}$, and suppose $h^{-1}(s)=\left\{\left(a^{t}, b^{1-t}\right): t_{1} \leqq t \leqq t_{2}\right\}$, then there exists $w \in(0, \infty)$ such that $h^{-1}\left(s^{\prime}\right)=\left\{\left(a^{w t}, b^{w-w t}\right): t_{1}^{\prime} \leqq t \leqq t_{2}^{\prime}\right\}$.

Proof. Let $h\left(x_{1}, y_{1}\right)=s$ and $h\left(x_{2}, y_{2}\right)=s^{\prime}$. From the previous lemma we know there exist $c, d \in(0,1)$ such that $h^{-1}\left(s^{\prime}\right)=\left\{\left(c^{t}, d^{1-t}\right)\right.$ : $\left.t_{1}^{\prime} \leqq t \leqq t_{2}^{\prime}\right\}$. For $(x, y) \in h^{-1}(s) \cdot\left(x_{2}, y_{2}\right)$ we have $h(x, y)=s s^{\prime}$, also for $\left(x^{\prime}, y^{\prime}\right) \in\left(x_{1}, y_{1}\right) h^{-1}\left(s^{\prime}\right)$ we have $h\left(x^{\prime}, y^{\prime}\right)=s s^{\prime}$. But $h^{-1}(s) \cdot\left(x_{2}, y_{2}\right)=\left\{\left(a^{u \delta}\right.\right.$, $\left.\left.b^{u-u \tilde{\delta}}\right): \delta_{1} \leqq \delta \leqq \delta_{2}\right\}$ and $\left(x_{1}, y_{1}\right) h^{-1}\left(s^{\prime}\right)=\left\{\left(c^{v \eta}, d^{v-v \eta}\right): \eta_{1} \leqq \eta \leqq \eta_{2}\right\}$. However, there exist $p, q \in(0,1)$ such that $h^{-1}\left(s s^{\prime}\right)=\left\{\left(p^{2}, q^{1-\lambda}\right): \lambda_{1} \leqq \lambda \leqq \lambda_{2}\right\}$. This implies $a^{u}=p=c^{v}, b^{u}=q=c^{v}$ or $c=a^{u / v}, d=b^{u / v}$.

Notation. Let Comp $\left(a^{w}, b^{1-w}\right)$ be the component of $h^{-1}(J) \cap\left\{\left(a^{t}\right.\right.$, $\left.\left.b^{1-t}\right): 0 \leqq t \leqq 1\right\}$ containing $\left(a^{w}, b^{1-w}\right)$.

Lemma 9. If $s \in J \backslash\{z\}$, and if $\left\{\left(a^{t}, b^{1-t}\right): t_{1} \neq t_{2}\right.$ and $\left.t_{1} \leqq t \leqq t_{2}\right\} \subset$ $h^{-1}(s)$, then $h^{-1}(s)=\operatorname{Comp}\left(a^{t_{1}}, b^{1-t_{1}}\right)$.

Proof. Let $\left(a^{w}, b^{1-w}\right) \in \operatorname{Comp}\left(a^{t_{1}}, b^{1-t_{1}}\right)$ and suppose $w<t_{1}$ and $h\left(a^{w}, b^{1-w}\right)=s^{\prime} \neq s$. Now $\left\{h\left(a^{t}, b^{1-t}\right): w \leqq t \leqq t_{1}\right\}$ is a curve in $J$ containing $s$ and $s^{\prime}$. Also for each $q \in\left[w, t_{1}\right]$ there exist $\beta_{q}, \gamma_{q}$ such that $\beta_{q}<\gamma_{q}$ and $h^{-1}\left(a^{q}, b^{1-q}\right)=\left\{\left(a^{t}, b^{1-t}\right): \beta_{q} \leqq t \leqq \gamma_{q}\right\}$. Moreover, for $s_{1}, s_{2} \in$ and $s_{1} \neq s_{2}$ we have $h^{-1}\left(s_{1}\right) \cap h^{-1}\left(s_{2}\right)=\varnothing$. Hence $\left\{h^{-1}(s): s \in\left\{h\left(a^{t}, b^{1-t}\right)\right.\right.$ : $\left.\left.w \leqq t \leqq t_{1}\right\}\right\}$ is an uncountable collection of disjoint closed intervals contained in the interval $\left\{\left(\mathrm{a}^{t}, b^{1-t}\right): 0 \leqq t \leqq 1\right\}$. This is impossible.

LEMma 10. If $s \in J$, then $s S=s U=s V$.

Proof. If $s=z$, then $z S=z U=z V=\{z\}$. Let $s \neq z$ and $h(x, y)=$ $s=h\left(x^{\prime}, y^{\prime}\right)$ with $x>x^{\prime}$ and $y^{\prime}>y$. Choose $x^{\prime \prime}, y^{\prime \prime}$ such that $x x^{\prime \prime}=x^{\prime}$ and $y^{\prime} y^{\prime \prime}=y$. Let $(\bar{x}, 1) \in\left\{(t, 1): x^{\prime \prime} \leqq t \leqq 1\right\}$. We will show there exists $(1, \bar{y}) \in\left\{(1, s): y^{\prime \prime} \leqq s \leqq 1\right\}$ such that $s \cdot h(\bar{x}, 1)=s \cdot h(1, \bar{y})$. Now $s \cdot h(\bar{x}, 1)=h(x, y) \cdot h(\bar{x}, 1)=h(x \bar{x}, y)$ and $x \geqq x \bar{x} \geqq x^{\prime}$. Hence there exists a unique $\widetilde{y}$ such that $y \leqq \widetilde{y} \leqq y^{\prime}$ and $h(x \bar{x}, \widetilde{y})=s$. Choose $\widetilde{y}$ such that $\bar{y} \widetilde{y}=y$. We see $y^{\prime \prime} \leqq \bar{y} \leqq 1$, and

$$
\begin{aligned}
s \cdot h(1, \bar{y}) & =h(x \bar{x}, \widetilde{y}) \cdot h(1, \bar{y})=h(x \bar{x}, \bar{y} \widetilde{y})=h(x \bar{x}, y) \\
& =h(x, y) \cdot h(\bar{x}, 1)=s \cdot h(\bar{x}, 1) .
\end{aligned}
$$

The same method yields for each $(1, \bar{y}) \in\left\{(1, s): y^{\prime \prime} \leqq s \leqq 1\right\}$ an $(\bar{x}, 1) \in$ $\left\{(t, 1): x^{\prime \prime} \leqq t \leqq 1\right\}$ such that $s \cdot h(1, \bar{y})=s \cdot h(\bar{x}, 1)$. Let $s^{\prime} \in S$. Then there exist $m, n$ positive integers and $x_{0}, y_{0}$ such that $x^{\prime \prime} \leqq x_{0} \leqq 1, y^{\prime \prime} \leqq y_{0} \leqq 1$ and 
such that $h\left(x_{0}^{n}, y_{0}^{m}\right)=s^{\prime}$. Hence $s \cdot s^{\prime}=s \cdot h\left(x_{0}^{n}, y_{0}^{m}\right)=s \cdot h\left(x_{0}, 1\right)^{n} h\left(1, y_{0}\right)^{m}$. But there exist $\hat{x}, \hat{y}$ such that $x^{\prime \prime} \leqq \hat{x} \leqq 1$ and $y^{\prime \prime} \leqq \hat{y} \leqq 1$ and

$$
s \cdot h\left(x_{0}, 1\right)^{n} \cdot h(\widehat{x}, 1)^{m}=s \cdot h\left(x_{0}, 1\right)^{n} \cdot h\left(1, y_{0}\right)^{m}=s \cdot h(1, \widehat{y})^{n} \cdot h\left(1, y_{0}\right)^{m} .
$$

That is $s \cdot U=s \cdot S=s \cdot V$.

Lemma 11. $h^{-1}(J) \cap(\{1\} \times I)=\{(1,0)\}$ or $h^{-1}(J) \cap(I \times\{1\})=\{(0,1)\}$.

Proof. Suppose this is false. Then there exist $(x, 1),(1, y) \in h^{-1}(J)$ and $0<x<1$ and $0<y<1$. From the previous theorem, letting $h(x, 1)$ represent the element $s$, we obtain $x^{\prime} \neq 0$ such that $h(x, 1) h(1, y)=$ $h(x, 1) \cdot h\left(x^{\prime}, 1\right)=h\left(x x^{\prime}, 1\right)$. Also letting $h(1, y)$ represent the element $s$, we get $y^{\prime} \neq 0$ such that $h(x, 1) h(1, y)=h\left(1, y^{\prime}\right) h(1, y)=h\left(1, y y^{\prime}\right)$. So $h\left(x x^{\prime}, 1\right)=h\left(1, y y^{\prime}\right)$. But this contradicts the assumption that $U \cap V=\{z, i\}$.

Lemma 12. If $(1, d) \in h^{-1}(J)^{*}$, then $(1, c) \in h^{-1}(J)$ for $0 \leqq c \leqq d$.

Proof. Let $(1, d) \in h^{-1}(J)^{*}$. One sees immediately that $\{(x, y)$ : $0 \leqq x<1,0 \leqq y<d\} \subset h^{-1}(J)$. Let $a, b \in(0,1)$ be as in Lemma 7 . For $0<c<d$ we have $(1, c)=\left(1, b^{w}\right)$, and hence there exists $t$, such that $\left\{\left(a^{t w}, b^{w-t w}\right): 0<t<t_{1}\right\} \subset h^{-1}(J)$. From Lemma 9 there exists an $s \in S$ such that $h\left(a^{w t}, b^{w-w t}\right)=s$ for $t \in\left(0, t_{1}\right)$. Using the continuity of $h$ we get $\lim _{t \rightarrow 0} h\left(a^{w t}, b^{w-w t}\right)=h\left(1, b^{w}\right)=s$. That is $(1, c) \in h^{-1}(J)$. For $c=0, h(1, c)=h(1,0)=z$ which is always in $J$.

The same method of proof also shows that if $(d, 1) \in h^{-1}(J)^{*}$, then $(c, 1) \in h^{-1}(J)$ for $0 \leqq c<d$.

Corollary 13. If $(x, 1),(1, y) \in h^{-1}(J)^{*}$, then $x=0$ or $y=0$.

Let $S$ be a commutative semigroup satisfying property $(\alpha)$. If $J \neq\{z\}$, then there exist $a, b \in(0,1)$ which satisfies the conditions of Lemma 7. If $J=\{z\}$, let $a=1 / 2, b=1 / 2$. From Theorem A we see that $(I, \cdot) \times(I, \cdot) / R\left(a, b, h^{-1}(J)^{*}\right)$ is a commutative semigroup satisfying property $(\alpha)$. Moreover, the following theorem holds.

Theorem B. The semigroups $S$ and $(I, \cdot) \times(I, \cdot) / R\left(a, b, h^{-1}(J)^{*}\right)$ are iseomorphic.

Proof. Consider the diagram

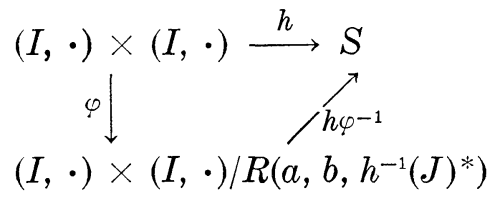


when $h$ and $\varphi$ are the maps described earlier. We will show the relation $h \varphi^{-1}$ is an iseomerphism. To prove this we need only show that for $(x, y) \in(I, \cdot) \times(I, \cdot), \varphi^{-1} \varphi(x, y)=h^{-1} h(x, y)$. Let $(x, y) \in(I, \cdot) \times$ $(I, \cdot)$. If $x=0$ or $y=0$ then $\varphi^{-1} \varphi(x, y)=(\{0\} \times I) \cup(I \times\{0\})=$ $h^{-1} h(x, y)$. Also if $\varphi^{-1} \varphi(x, y)=\{(x, y)\}$, then $h^{-1} h(x, y)=\{(x, y)\}$. Suppose $\varphi^{-1} \varphi(x, y)$ is not a point and $\varphi^{-1} \varphi(x, y)=$ the component of $\left(h^{-1}(J)^{*} \cap\left\{\left(a^{t w}, b^{w-t w}\right): 0 \leqq t \leqq 1\right\}\right)$ containing $(x, y)=\left\{\left(a^{w t}, b^{w-w t}\right): t_{1} \leqq\right.$ $\left.t \leqq t_{2}, t_{1} \neq t_{2}\right\}$. Hence $\left\{(c, d): c<a^{w t}, d<b^{w-w t}\right.$, for some $\left.t \in\left[t_{1}, t_{2}\right]\right\} \subset$ $h^{-1}(J)$. Let $w_{n}=w^{1+(1 / n)}, n=1,2,3, \cdots$, then $a^{w} n^{t}<a^{w t}$ and $b^{w_{n}-t w}<$ $b^{w-t w}$ for $t_{1} \leqq t \leqq t_{2}$. This implies $\left\{\left(a^{w_{n} t}, b^{w_{n}-w_{n} t}\right): t_{1} \leqq t \leqq t_{2}\right\} \subset h^{-1}(J)$. Using Lemma 9 we see

$$
h\left(a^{w_{n} t_{1}}, b^{w_{n}-w_{n} t_{1}}\right)=h\left(a^{w_{n} t}, b^{w_{n}-w_{n} t}\right)=h\left(a^{w_{n} t_{2}}, b^{w_{n}-w_{n} t_{2}}\right)
$$

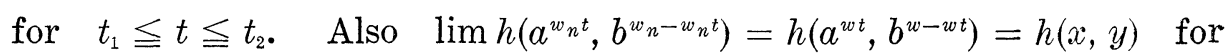
$t_{1} \leqq t \leqq t_{2}$. And we have $h^{-1} h(x, y)=\phi^{-1} \varphi(x, y)$. The induced homomorphism theorem implies $h \varphi^{-1}$ is an iseomorphism.

I wish to thank Professor Haskell Cohen for his understanding help. Also I would like to thank Dr. J. T. Borrego for his helpful comments.

\section{BIBLIOGRAPHY}

1. D. R. Brown, Topological semilattices on the two-cell, Pacific J. Math. 15 (1965) 35-46.

2. H. Cohen and H. S. Collins, Affine semigroups, Trans. Amer. Math. Soc. 93 (1959), 97-113.

3. H. Cohen and L. I. Wade, Clans with zero on an interval, Trans. Amer. Math. Soc. 88 (1958), 523-535.

4. W. M. Faucett, Compact semigroups irreducibly connected between two idempotents, Proc. Amer. Math. Soc. 6 (1955), 741-747.

5. J. A. Hildebrant, On uniquely divisible semigroups on the two-cell, Pacific J. Math. 23 (1967), 91-95.

6. Anne Lester, Some semigroups on the two-cell, Proc. Amer. Math. Soc. 10 (1959), 648-655.

7. P. S. Mostert and A. L. Shields, On the structure of semigroups on a compact manifold with boundary, Ann. of Math. 65 (1957), 117-143.

8. G. T. Whyburn, Analytic topology, Providence, Rhode Island; Amer. Math. Soc. Colloquium Publications, Vol. 28, 1942.

Received February 17, 1969. This paper contains part of a doctoral dissertation written under the direction of Professor Haskell Cohen.

Wichita State University 



\section{PACIFIC JOURNAL OF MATHEMATICS}

\section{EDITORS}

H. SAMELSON

Stanford University

Stanford, California 94305

\section{Richard Pierce}

University of Washington

Seattle, Washington 98105
J. DugundJI

Department of Mathematics

University of Southern California

Los Angeles, California 90007

RICHARD ARENS

University of California

Los Angeles, California 90024

\section{ASSOCIATE EDITORS}

\section{E. F. BeCKenBACH}

B. H. NeUmanN
K. YosHida

\section{SUPPORTING INSTITUTIONS}

\author{
UNIVERSITY OF BRITISH COLUMBIA \\ CALIFORNIA INSTITUTE OF TECHNOLOGY \\ UNIVERSITY OF CALIFORNIA \\ MONTANA STATE UNIVERSITY \\ UNIVERSITY OF NEVADA \\ NEW MEXICO STATE UNIVERSITY \\ OREGON STATE UNIVERSITY \\ UNIVERSITY OF OREGON \\ OSAKA UNIVERSITY \\ UNIVERSITY OF SOUTHERN CALIFORNIA
}

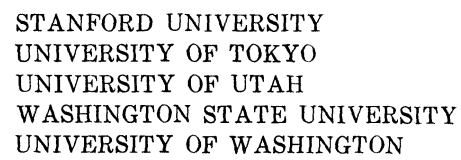

STANFORD UNIVERSITY UNIVERSITY OF TOKYO

UNIVERSITY OF UTAH

WASHINGTON STATE UNIVERSITY

UNIVERSITY OF WASHINGTON

The Supporting Institutions listed above contribute to the cost of publication of this Journal, but they are not owners or publishers and have no responsibility for its content or policies.

Mathematical papers intended for publication in the Pacific Journal of Mathematics should be in typed form or offset-reproduced, (not dittoed), double spaced with large margins. Underline Greek letters in red, German in green, and script in blue. The first paragraph or two must be capable of being used separately as a synopsis of the entire paper. The editorial "we" must not be used in the synopsis, and items of the bibliography should not be cited there unless absolutely necessary, in which case they must be identified by author and Journal, rather than by item number. Manuscripts, in duplicate if possible, may be sent to any one of the four editors. Please classify according to the scheme of Math. Rev. Index to Vol. 39. All other communications to the editors should be addressed to the managing editor, Richard Arens, University of California, Los Angeles, California, 90024.

50 reprints are provided free for each article; additional copies may be obtained at cost in multiples of 50 .

The Pacific Journal of Mathematics is published monthly. Effective with Volume 16 the price per volume (3 numbers) is $\$ 8.00$; single issues, $\$ 3.00$. Special price for current issues to individual faculty members of supporting institutions and to individual members of the American Mathematical Society: $\$ 4.00$ per volume; single issues $\$ 1.50$. Back numbers are available.

Subscriptions, orders for back numbers, and changes of address should be sent to Pacific Journal of Mathematics, 103 Highland Boulevard, Berkeley, California, 94708.

PUBLISHED BY PACIFIC JOURNAL OF MATHEMATICS, A NON-PROFIT CORPORATION

Printed at Kokusai Bunken Insatsusha (International Academic Printing Co., Ltd.), 7-17, Fujimi 2-chome, Chiyoda-ku, Tokyo, Japan. 


\section{Pacific Journal of Mathematics}

\section{Vol. 34, No. 3 \\ July, 1970}

Richard Hindman Bouldin, The peturbation of the singular spectrum

Hugh D. Brunk and Søren Glud Johansen, A generalized Radon-Nikodym derivative .

Henry Werner Davis, F. J. Murray and J. K. Weber, Families of $L_{p}$-spaces

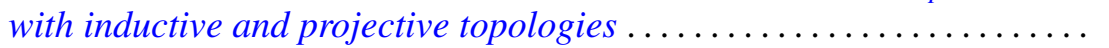

Esmond Ernest Devun, Special semigroups on the two-cell .

Murray Eisenberg and James Howard Hedlund, Expansive automorphisms

of Banach spaces ......................................

Frances F. Gulick, Actions of functions in Banach algebras.

Douglas Harris, Regular-closed spaces and proximities.

Norman Lloyd Johnson, Derivable semi-translation planes . .

Donald E. Knuth, Permutations, matrices, and generalized Young

tableaux..........................................

Herbert Frederick Kreimer, Jr., On the Galois theory of separable

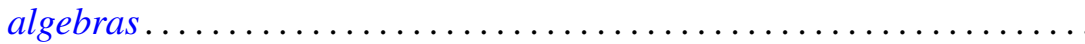

You-Feng Lin and David Alon Rose, Ascoli's theorem for spaces of

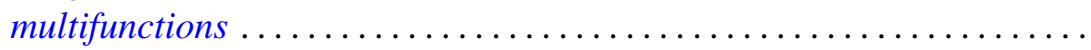

David London, Rearrangement inequalities involving convex functions . . . .

Louis Pigno, A multiplier theorem.

749

Helga Schirmer, Coincidences and fixed points of multifunctions into trees.

755

Richard A. Scoville, Some measure algebras on the integers .

Ralph Edwin Showalter, Local regularity of solutions of Sobolev-Galpern

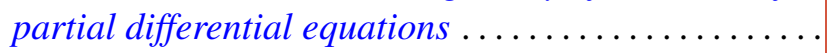

Allan John Sieradski, Twisted self-homotopy equivalences

John H. Smith, On S-units almost generated by S-units of subfields ...

803

Masamichi Takesaki, Algebraic equivalence of locally normal

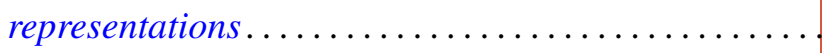

Joseph Earl Valentine, An analogue of Ptolemy's theorem and its converse in

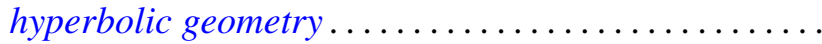

David Lawrence Winter, Solvability of certain p-solvable linear groups of finite order 